\title{
French CEO Compensations: What is the Cost of a Mandatory Upper Limit?
}

\author{
FABIENNE LLENSE
}

CESIFO WORKING PAPER NO. 2402

CATEGORY 4: LABOUR MARKETS

SEPTEMBER 2008 Presented At CESIFO VeniCe SuMmer InStituTe 2008,
WORKSHOP ON EXECUTIVE PAy

\footnotetext{
An electronic version of the paper may be downloaded

- from the SSRN website: www.SSRN.com

- from the RePEc website: - from the CESifo website: 


\title{
French CEO Compensations: What is the Cost of a Mandatory Upper Limit?
}

\begin{abstract}
In the middle of the nineties, the sharp increase in globalisation and the last privatization wave have promoted the shaping of a market for executives in France. Characteristics of this market are estimated for France and a competitive model is simulated in order to assess to what extend such a model could explain the observed CEO compensations. The size elasticity of compensation in France is equal to 0.5 and justifies a large magnitude in compensation. To moderate those compensations, a wage cap is often called for by opinion and the European left but also, more surprisingly, by representative of shareholders. The cost of this policy is evaluated in this sorting model and the lobbying of shareholders is explained.
\end{abstract}

JEL Code: J31, J33, D33, D41.

\author{
Fabienne Llense \\ Paris School of Economics and \\ University of Paris I \\ CES (ex-EUREQUa) \\ 106-112 bld de l'Hôpital \\ 75647 Paris Cedex 13 \\ France \\ Fabienne.Llense@univ-paris1.fr
}

August 2008 


\title{
French CEO Compensations: What is the cost of a mandatory upper limit?
}

\author{
Fabienne Llense *
}

August 2008

\section{Introduction}

The French public has recently focussed its interest on executive pay for two main reasons. The first is the disclosure of CEO and other executive compensations imposed by the Law of 15 May 2001. The second is the double-digit growth of $\mathrm{CEO}$ compensations compared to the $0.7 \%$ growth rate by year of mean earning during the last decade. Generally, the rapid rise of french CEO compensations has been interpreted as catching-up with Anglo-saxon's, and more particularly with american CEO compensations. The catching-up explanation assumes an international market, with international opportunities given to French executives. However, as real mobility is limited, French CEO compensation should be linked to the evolution of the French market rather than an international catching-up. Since the second privatisation wave (1993-1997), the number of large publicly-traded firms has increase and the mean CEO compensation for companies listed on the SBF120 index,is about $\epsilon 3,000,000$ in 2006 . This article tests, in a first part, the hypothesis of market-driven compensation

* Paris school of economics and University of Paris 1 , CES (ex-EUREQua) 106-112 bld de l'Hôpital 75647 Paris Cedex 13; Email: Fabienne.Llense@univ-paris1.fr 
for French CEO following from this shaping of a competitive market.

A competitive equilibrium model, linked to job assignment and superstar theory, is developed, in order to assess how much of the french CEO compensations explosion can be explained in a competitive framework. The superstar theory analyses the rise in stars' compensations in a competitive process. The rise is explained by the imperfect substitution between stars' talents on the offer side and the extension of the market by technology on the demand side (Rosen $1981[12])$. As the talent appears relevant to analysing very high earnings, this raises the question of the existence and characteristics of CEO talent. The talent existence has been underscored by the significant CEO fixed effects on the perfrmance of large US firms (Schoar and Bertrand 2003 [1]). The fixed effects refer to different management styles linked to CEO characteristics (MBA degree, cohort). Nevertheless, the regression of compensation on observable CEO attributes, such as age or formal qualification, are non-significant, meaning that CEO compensations could not be estimated using a Mincer wage equation. As the observable characteristics are not sufficient to specifiy talent heterogeneity, the $\mathrm{CEO}$ talents could be modelized by a general tail distribution based on the extrem values theory (Gabaix and Landier 2007 [4]). In a context in which the compensation distribution differs from the expected talent distribution, the job assignment theory by introducing job characteristics could explain CEO compensation distribution (Sattinger 1993 [8]). By matching heterogenous CEOs to heterogenous jobs, wages play an allocative role in assigning talent to firm sizes. The shape of the allocation and the intensity of skew depend on the complementarity between inputs. The assumption of complementarity implies that output sensitivity to talent increases with firm size, leading to an allocation between the most talented CEO and the largest firm, called a positive assortative matching (Becker 1973 [5]). Firm sizes, CEO talents and the shape of the matching function are key factors in wage determination, in a competitive market (Tervio $2003[9])$.

In line with the competitive Gabaix and Landier paper, a reference framework is built here to analyse CEO wage distribution on french CEO market. A 
differential rents model, defined as a job assignment model in which the variable distributions are continuous, is developed in order to express wages as a function of size and talent distribution parameters, and of the firm size itself. The wage function is decomposed to better understand the size effect and its interaction with talent through the positive assortative matching. Whereas CEO compensations and firm sizes are observable, CEO talent is difficult to measure. The theoretical relationship, through the differential rents model, between compensations and sizes leads to estimate the underlying talent distribution needed to generate the French CEO compensation levels The results suggest that to generate the french CEOs compensations, in a competitive framework, the talent distribution has to be spread and concentrated in higher talents, i.e the marketperception of differences between CEO is less homogeneous than for US.

The estimated parameters of the talent distribution are introduced to simulate the theoretical $\mathrm{CEO}$ compensation function in the competitive framework previously build for the French economy. By simulating French compensations in different scenario, the potential evolution of the size elasticity of wages, and the level reached at equilibrium are found and compare with empirical data. Interestingly, the simulations lead to both elasticity and the shape of the surplus share evaluations, which extend the normative interest of this analysis. It includes the opportunity of both better understanding the fundamental relationship between wage and size through the evolution of distribution parameters such as the talent and size concentration, as well as another opportunity to examine the french case. The 0.5 empirical size elasticity of compensation in France is reproduced in the simulations. The elasticity analysis indicates that the model may provide a general framework to understand the specificity and the non linear relationship between the size elasticity of CEO compensations and parameters of the size and talent distribution. This framework helps to summarize results concerning the effects of the distribution of non invariant factor on compensations structure. The simulated compensation function in a competitive framework explains a large share of the observed compensation levels, but seems unable to explain the existence of groups of compensation be- 
yond 8 million euro for middle cap firms and some other compensations under the predicted competitive compensation for the smallest firms. Some others investigations must be done to insulate the imperfection on this specific market.

There is undoubtedly a gap between actual CEO pay and what people regard as fair compensations. This observation leads the European politicians to address the subject considering the feasibility of a ceiling for the highest compensations and suggesting a moderate ratio between the workers (blue and white collars) and the chief executive officer, as Angela Merkel position testify. This paper introduces a cap policy in the framework of a sorting model in order to assess the effect of such a regulatory limitation on the shareholder wealth, the $\mathrm{CEO}$ earnings and the production. The main concern about the use of a limitation is: how attract the right $\mathrm{CEO}$ for the right job? Indeed, the introduction of a cap policy neutralizes the allocative role of the compensation leading to a costly mismatch. Simulations of the model for different upper limits are able to explain why some consulting firms and shareholder association call for a wage cap.

\section{The job assignment framework}

On this market, there are two sources of heterogeneity: the ability of the CEO and the size of the firm. Given this heterogeneity which is perfectly observable, shareholders choose the best CEO to manage their firm. This matching issue is resolved in two steps.

In a first step, the equilibrium allocation function is specified, then, in a second step, the system of prices (CEO compensations) that sustains this matching is found. Let $t \in\left[t_{0}, t_{\max }\right]$ denote the ex ante market-perception (Board of directors) of the CEO talent and $s \in\left[s_{0}, s_{\max }\right]$ denote the firm size (market value), both are unidimentional. Individuals and firms are considered as a unit mass such that at the equilibrium there is full employement. The distributions of those inputs are continuous and characterized by CDF denoted, $F(t)$ for talent distribution and $G(s)$ for size distribution with $j=F(t)$ the talent quantile of 
CEO and $i=G(s)$ the size quantile of firm into the distribution. The quantity of work provides by a CEO could not be increased neither in an intensive margin (through effort or time) nor in an extensive one (through hiring). All the CEOs provide the same effort, the only sorting characteristic is the ability and consequently there is no moral hazard issue. Hence, a fixed amount of capital is allocated with a fixed amount of ability. This indivisibility is taken into account in job assignment model and implies that the marginal productivity of factors is a separate concept relative to the classical one. The production function $\mathrm{Y}($.$) is$ twice continuously differentiable and is characterized by increasing differences:

$$
\frac{\partial^{2} Y(t, s)}{\partial t \partial s}>0
$$

This expression (1) describes the Scale-of-Operation effect that consists on allocating the largest ressources to the best manager given that the marginal impact of CEO talent is assumed to increase with the value of assets under his control. This assumption is built on the complementarity between firm size and CEO ability. The elasticity of substitution is weak in order to represent the rigid repartition due to indivisibility of factors of production. In this model, firms sizes are independant from the CEO ability. However, the size of the assets managed by CEO have been increased through the NICT developpement (Acquistions and mergers are easier thanks to the increasing volume of informations and transactions which could be executed), which enhanced the complementarity between the two inputs and enable CEO to manage more and more larger firms.

Definition 1 The competitive equilibrium consists in: (i) a matching function $M($.$) which allocates a firm from the i-quantile to a CEO from the j-quantile$ such that $j=M(i), i, j \in[0,1]$; and (ii) a wage function $w(j)$, which verifies the two following conditions: (a) each firm selects the j:th CEO which maximize the shareholder value $\pi(j, i)$ st:

$$
\operatorname{Max}_{j} Y(t(j), s(i))-w(j)
$$


and (b) both the participation constraint of the CEO $\left(w_{0}\right)$ and of the owners $\left(\pi_{0}\right)$, i.e the reserve prices are fulfilled:

$$
\begin{gathered}
w(j) \geqslant w_{0} \quad \forall j \in[0,1] \\
\pi(j, i)=Y(t(j), s(i))-w(j) \geqslant \pi_{0} \quad \forall i, j \in[0,1]
\end{gathered}
$$

The CEO utility of reservation is $w_{0}$ and the shareholders utility of reservation is $\pi_{0}$.

The first order condition is obtained. The slope of the profile equals the product of the partial derivative of output with respect to productive ability, i.e the job sensitivity to ability and the ability spacing at this level:

$$
w^{\prime}(j)=t^{\prime}(j) Y_{1}(t(j), s(i))
$$

At the equilibrium, each firm maximizes its profit (2) by filling up the condition (5). According to the complementarity described by $(1): \frac{\partial}{\partial s(i)}\left(Y_{1}(t(j), s(i))\right)>$ 0 , the largest is the firm, the highest is the ability return. Consequently, each $\mathrm{CEO}$ has preference for working in the largest firm. By the same way, because of the complementarity between the input, talent and assets, a biggest firm is more sensible to ability than a smaller one and so wishes to hire the most able $\mathrm{CEO}$. At the equilibrium, highest ability CEO t(1) is placed in the largest firms $s(1)$ chooses the best CEO, and the second firm mates the second best and so forth. The equilibrium match is a positive assortative matching with $\mathrm{M}($.$) , the$ identity function. The first order condition (5) becomes:

$$
w^{\prime}(i)=t^{\prime}(i) Y_{1}(t(i), s(i)) \quad \forall i \epsilon[0,1]
$$

By integrating (6) and according to the participation constraint the wage 
structure $^{1}$ is the following:

$$
w(i)=w_{0}+\int_{0}^{i} t^{\prime}(j) Y_{1}(t(j), s(j)) d j
$$

The absolut wage levels are determined by the reserve price $w_{0}$ and the differential rents themselves determined by the localisation of the firm-CEO pair into the distribution. The prices of inputs exhaust the product: $Y(i, i)=\pi(i)+w(i), \forall i$. Thus, the free entry condition depends on the link between reservation prices and the match formed by the last CEO and the smallest firm: $Y(t(0), s(0))=$ $\pi_{0}+w_{0}$. Hence, at the equilibrium, the last firm's profit is driven down by opportunity costs in equilibrium.

Limits cases There will be no differential rents and no assignment issue if all the CEOs have the same talent. The CEOs will be paid exactly the same total pay whatever the firm size. This compensation would be exactly equal to their common reservation wage $w_{0}$, given that there is no extra costs to manage a larger corporation (Bertrand competition). Similarly, if all the firms have the same size, CEO earned exactly their joint production and the wage distribution would be like the talent distribution.

Following Tervio (2005), a new matching function $\varphi($.$) is used to express$ wages as a function of the firms size only:

$$
t=\varphi(s) \text { s.t } \quad F(t)=G(s)
$$

The wage function is written:

$$
w(s)=w_{0}+\int_{s_{0}}^{s} \varphi^{\prime}(x) Y_{1}(\varphi(x), x) \mathrm{dx}
$$

with $\varphi^{\prime}(s)$ the matching function slope: $\varphi^{\prime}(s)=\frac{G^{\prime}(s)}{F^{\prime}(\varphi(s))}>0$

This latter equation is the ratio of the potential demand for talent for the potential offer which is composed of substitute talents. The matching slope is

\footnotetext{
${ }^{1}$ Similarly:

$$
\pi^{\prime}(i)=s^{\prime}(i) Y_{2}(t(i), s(i))
$$

and:

$$
\pi(i)=\pi_{0}+\int_{0}^{i} s^{\prime}(j) Y_{2}(t(j), s(j)) \mathrm{dj}
$$
}


a kind of tension index on the CEO market for each firm size. This matching function is increasing and concave in $s$ :

$$
\begin{array}{r}
w^{\prime}(s)=\varphi^{\prime}(s) Y_{1}(\varphi(s), s) \\
w^{\prime \prime}(s)=\varphi^{\prime \prime}(s) Y_{1}(\varphi(s), s)+\varphi^{\prime}(s)\left[Y_{1,1}(\varphi(s), s)+\varphi^{\prime}(s) Y_{2,0}(\varphi(s), s)\right]
\end{array}
$$

With $Y_{2,0}(\varphi(s), s) \leqslant 0$ and $Y_{1,1}(\varphi(s), s)>0$ due to the complementarity. The wage equation is concave if $\varphi^{\prime \prime}(s) Y_{1}(\varphi(s), s)+\varphi^{\prime}(s) Y_{1,1}(\varphi(s), s)<0$, when $\varphi($.$) is sufficiently concave function: \varphi^{\prime \prime}(s)<0$, i.e the sizes are more inequaly distributed than CEO ability.

The compensation increases according to the complementarity of input (1), through both the positive assortative matching and the tension on this portion of the market. At the equilibrium, the wage is an increasing function in the reservation salary, the firm size and the demand, both the number of firm and the density and a decreasing function in the offer (potential substitution).

\section{Comparative Statics and differential rents}

\subsection{The distribution choice}

Firm size cumulative distribution function

In order to represent the distribution of large publicly-traded firms, a Pareto distribution $G($.$) is selected; this assumption is very usual, see Takayasu and$ Okuyama (1998 [6]), Axtell (2006 [11]), Gabaix and Landier (2007). This distribution is defined by the tail index (shape parameter) $\alpha$ and the scale parameter $s_{0}$, the minimum firm size on the market: $G(s)=1-\left(\frac{s}{s_{0}}\right)^{-\alpha}$.

This function is increasing in $s$ and $\alpha$ and decreasing in $s_{0}$. Moreover the size is inversely proportionnal to its rank such that: $S(n)=\mathrm{An}^{-\frac{1}{\alpha}}$ with $A=\frac{s_{0}}{K^{\frac{-1}{\alpha}}}$. Proof $G(s)=i$ so $1-i=\left(\frac{s}{s_{0}}\right)^{-\alpha}$ the rank $n \in[0, K]$ corresponds to the i-quantile $s$ and $K$ is the rank of the least able. The quantile-rank relation is given by $1-i=\frac{n}{K}$

$$
n=\left(\frac{s}{s_{0}}\right)^{-\alpha} K \text { also written } s=\left(\frac{n}{K}\right)^{-\alpha} s_{0} .
$$




\section{Ability cumulative distribution function}

Using Gabaix and Landier (2007) talent distribution, talents' spacings could be described by a very general relation: $\quad t^{\prime}(i)=B L(1-i)(1-i)^{\beta-1}$ with $L($.) a slowing variable function, $\beta$ the tail index of the distribution of talents and $B$ the scale parameter. Talents are assumed to be bounded consequently $L($.$) is a constant and the shape parameter is positive \beta>0$. The cumulative distribution function is written:

$$
F(t)=1-C\left(t_{\max }-t\right)^{\frac{1}{\beta}}, \quad t<t_{\max }<\infty
$$

Gabaix and Landier write the talent according to the rank $n \in[0, K]: T(n)=$ $-\frac{B}{\beta}\left(n^{\beta}-K^{\beta}\right)$ with $K$ the rank of the least able. The talent of the more able is written: $t_{\max }=t(1)=T(0)=\frac{B}{\beta} K^{\beta}$. From the relationship between rank and quantile previously mentioned: $n=K(1-i), \forall i \in[0,1]$ and $n \in[0, K]$. So I obtain the talent-quantile relation:

$$
t(i)=-\frac{B}{\beta}\left[(K-K i)^{\beta}-K^{\beta}\right]
$$

We choose the cumulative distribution function $\mathrm{F}($.$) so that i=F(t)$ :

$$
F(t)=1-C\left(t_{\max }-t\right)^{\frac{1}{\beta}}
$$

with $C=\frac{1}{K}\left(\frac{\beta}{B}\right)^{\frac{1}{\beta}}$ and $L=K^{\beta}$. So, $F($.) is constructed such that the talent distribution is a power law with finite support.

The wage function

As previously mentioned: $\left.w(s)=w_{0}+\int_{s_{0}}^{s} \frac{g(s)}{f(\varphi(s))} Y_{1}(\varphi(s)), s\right) d s$. With the chosen distribution, the wage function could be rewritten as an explicit function of all the parameters and the firm size:

$$
w(s)=w_{0}+\frac{\alpha s_{0}^{\alpha \beta} K^{\beta} B}{(1-\alpha \beta)}\left(s^{1-\alpha \beta}-s_{0}^{1-\alpha \beta}\right)
$$

The wage is always increasing in the size of the firm, but concave. Gabaix and Landier have highlighted the impact of the median size, which is a synthese of the size distribution parameters, without taking into account the role plays by the firm localisation (quantile) into the distribution. On the contrary, Tervio 
(2007) does but without a tractable talent distribution. In the two following parts, the impact of the size on the CEO wage is divided into a direct and indirect size effect through the study of the sensitivity of wages to size according to the distribution parameters and the localisation of the firm.

\subsection{The effects of size and talent distribution on the wage- size relationship}

The sensitivity of wages to the firm size is enhanced or decreased according to the location of the firm in the distribution. This variation depends on the inequality parameters of the distributions. These shape parameters lead the differential rents. The impact of the size distribution on the wage sensitivity to the firm size is given by:

$$
\frac{\partial^{2} w(s)}{\partial s \partial \alpha}=\alpha K^{\beta} B\left(\frac{s_{0}}{s}\right)^{\alpha \beta}\left(\frac{1}{\alpha}+\beta \log \left(\frac{s_{0}}{s}\right)\right)
$$

The sign of the partial derivative is positive when the size of the firm is under the threshold $\widehat{s_{\alpha}}$, and negative otherwise, with:

$$
\widehat{s_{\alpha}}=s_{0} \operatorname{Exp}\left(\frac{1}{\alpha \beta}\right)
$$

This size corresponds to a rank $\widehat{n_{\alpha}}$ from which the slope of the wage function is diminishing with firm size. Whatever the variation of the Pareto tail index, the rank $\widehat{n_{\alpha}}$ is invariant with $\alpha$ as long as there is no entry.

Proof $\widehat{n_{\alpha}}=K\left(\operatorname{Exp}\left(\frac{1}{\alpha \beta}\right)\right)^{-\alpha}$ so $\frac{\partial \widehat{n_{\alpha}}}{\partial \alpha}=0$ and $\frac{\partial \widehat{n_{\alpha}}}{\partial \beta}=\frac{1}{\beta^{2}} K \operatorname{Exp}\left(\frac{1}{\alpha \beta}\right)^{-\alpha}>0$

If $G_{A}$ and $G_{B}$ are two cumulative distribution functions of size, with the same scale parameter $s_{0} . G_{A}$ dominates $G_{B}$ by first order stochastic dominance if: $G_{A}(s) \leq G_{B}(s)$. Meaning that, for all $s$, there is at least one $s_{k}$ such that $G_{A}\left(s_{k}\right)<G_{B}\left(s_{k}\right)$. On this case the relationship between the parameters is: $\alpha^{A}<\alpha^{B}$. A change from B to A distribution, due to globalisation for instance, raises sizes at all quantiles except for the smallest one. The new market is composed by more bigger firms and less smaller ones. Indeed, a decrease in $\alpha$ leads to more biggest firms in the economy, $\widehat{s_{\alpha}}$ increases but the rank of 
this threshold firm stays the same, $\widehat{n_{\alpha}}$. When $\alpha$ decreases, the more inequal size distribution implies a decrease in the wage sensitivity for firms under the threshold and an increase for firms above the threshold. The direct effect of the decrease of $\alpha$ results in a less sloping wage for the size below the threshold and a higher slope for the firms above the threshold. There could be second effect through the matching technology. Indeed, similarly,the wage sensitivity to talent distribution is characterised by the following equation:

$$
\frac{\partial^{2} w(s)}{\partial s \partial \beta}=\alpha K^{\beta} B\left(\frac{s_{0}}{s}\right)^{\alpha \beta}\left(\log (K)-\alpha \log \left(\frac{s}{s_{0}}\right)\right)
$$

The sign of the partial derivative is positive when the size of the firm is under the threshold $\widehat{s_{\beta}}$, and negative otherwise, with:

$$
\widehat{s_{\beta}}=s_{0} K^{\frac{1}{\alpha}}
$$

The rank of $\widehat{s_{\beta}}$ is written: $\hat{n}_{\beta}=1$. For a given $\beta$, when $\alpha$ decreases, the indirect effect lowers the positive size effect only for the highest quantile. To sum up, a decrease of $\alpha$ implies a less concave function (lower wage growth, i.e lower wage slope) for the firms below $\hat{n}_{\alpha}$ and higher wage growth for the firms above this threshold. The sensitivity of the largest firms has been reenforced, and so the resulting wage function is extended and the expected wages inequality is higher. CEO compensations are more spread, more inequaly distributed. Moreover, the more the wage is sensitive to the size the more the surplus is shared in favour of the CEO. As a result, the size elasticity of wage and the mean size elasticity of wages (more sensitivity for larger firms) are higher. At the same time, for a given size, the CEO compensation could be inferior to the previous compensation because this firm size corresponds, in the new configuration, to a lower quantile. Consequently, after a globalization process, CEO compensation levels are both higher and more inequaly distributed. ${ }^{2}$

\footnotetext{
${ }^{2}$ Median size $\left(s_{0} 2^{\frac{1}{\alpha}}\right)$ versus threshold $\widehat{s_{\alpha}}$ : the two sizes are only equal for a specific value of $\beta=1.44$. If $\beta>1$ and $\frac{1}{\beta}>\ln (2)$ or if $\beta<1$ then $\widehat{s_{\alpha}}>s_{\text {median }}$, otherwise $\widehat{s_{\alpha}}<s_{\text {median }}$. In a sectional analysis this threshold is more consistant to understand the non linear relationship between size and compensation.
} 
The same exercice is done for an increase in CEO talents: $F_{C}$ and $F_{D}$ two cumulative distribution function of talent, with the same scale parameter B. If $F_{C}$ dominates $F_{D}$ by first order stochastic dominance, then $\beta^{D}<\beta^{C}$. In the "C" case, CEO are more inequaly distributed and more talented in average. The tail index $\beta$ could be interpreted as the result of a screening process which, according to its properties (education, competition, exam), or according to the employers expectations (increasing and precise informations on the ability and career of each CEO, networks, role of the leader in the economic context) induces inequal degree of talent distribution. The bounds (upper and lower) of the distribution are invariant in order to determine the effects of talent improvement on a given scale of talents (when $\beta$ increases $B$ is lower). If $\beta$ increases, the CEO ability is regarded as better for each quantile except the first and the last ones. This increase in $\beta$ implies a higher sensibility of CEO compensation for firms under the threshold $\hat{n}_{\beta}$. Indeed, at theirs quantiles the competition is lower. At the contrary, the potential substitution intensity raises for the others quantiles. The intensity of the sensibility increase or decrease with $\beta$ but the number of firms of each sensibility stays equal. For the lowest quantiles there is more productivity and less substitution leading to an increase of their wage sensitivity and through the wage slope at their quantile. The slope of the wage function will be higher for the first quantiles (under the $\beta$ threshold) and lower after. At the same time $B$ (the space between $\mathrm{CEO}$ characteristics) decreases, the potential substitution is slightly increased at all quantiles and CEO differential rents would be lower. The increase in $\beta$ has also a second effect through the positive assortative matching, the $\widehat{n_{\alpha}}$ increases leading to an increase in the number of firms with lower wage sensitivity to size. In further section, simulations illustrate those comparative statics, and permit to discuss the value of the median size elasticity of wages.

Without shifts in the distributions (time-invariant), a change in the technology of production through uniform productivity growth (NICT) could be modelized. This uniform productivity growth reinforces the complementarity between talent and size. Two evolutions are feasible. Relative to the uniform shift in technology, the outside opportunites could change in lockstep such that 
they drive down the firm's profit, there is no entry. There are no change in the potential substitution and competition among firms, the same surplus share is kept and the wage slope is exactly the same but the increasing complementarity increases automatically the mean elasticity and so the wages. On the contrary, if reserve prices stay at the same level, new smaller firms could enter on the market by covering the reservation prices. The entrant firms have smaller size decreasing the wage distribution but the number of firms increases thanks to the activation of new firms increasing the wage distribution.

To test the explanatory power of this model, the parameters need to be estimated for France in order to carry out some simulations.

\section{French data and parameterization}

The previous model has allowed us to understand how market forces, through distribution of complement heterogenous inputs, drive the wage structure. Most of the components of the theoretical wage could be observed or calculated: the sizes of firms, the Pareto tail index, the real wages structure and the number of firms. Only the talent distribution parameters $\beta$ and $\mathrm{B}$ are unknown. An estimation of the french underlying talent distribution characterised by those parameters is performed. These estimates are obtained by a Generalised Method of Moments (GMM) estimation in order to minimize the digression between the observed and the predicted compensations described by the equation (13) which is non linear, without specification on earning distribution.

The data come from Proxinvest, a french independant consulting firm. Their data are only collected from corporate reports. For the purpose of this study, the largest sample available, the french index SBF120 is used. This index includes the 120 largest French publicly-traded firms, large-cap and mid-cap representing more than $75 \%$ of the total market capitalization of french listed companies. This study exploits the 2002-2005 data. The size of the sample, which prevents to use panel methodology, is the result of the french legislation which has required the disclosure of these information since 2001 and with more details since 
2005 only. Two series of data are used: CEO compensations and the firm sizes. All the data are in real terms, using the current compensations and the firm sizes deflated by the 2005 retail price index. ${ }^{3}$ The compensations are compiled with salary, bonus and the option values (using the Black and Scholes formula which is an ex ante assess), but ignoring deferred compensations and benefits. The year compensation is reconstructed by using salary, bonus, options and others compensations awarded for a specific year after their publication in the next year corporation reports. These compensations are calculated for the number one, i.e the better paid chief executive officer, denoted in french: "Président directeur général", "Directeur général", "Président du directoire", "Directeur général", "Président" or "Gérant". The only CEO dropped from the sample is Sir Lindsay Owen Jones due to the specificity of his outside opportunities which lead to regard him as a Anglo-saxon or American CEO.

Firm size has many measures in the literature: the number of employees, the turnover, the sales, or the market capitalization. The choice of the measure depends on the way CEO interact with firm assets. Consequently, the number of employees is not an appropriate measure even if it is the $\mathrm{INSEE}^{4}$ criterion to define firm size. According to the fundings of Bertrand and Schoar, CEO has very general actions and mostly in financial and strategic domains. Moreover, as emphasized by Baker and Hall, the marginal productivity of CEO talent or effort is relative to the real role play by these managers. The CEO links the firm to their shareholders and creditors through the implementation of strategic decisions (acquistion, dividend policy...). Thus, using the turnover does not take into account the firm potential and also the long term effect of CEO actions. Therefore, the more consistant size variable seems to be the market capitalization. Moreover, the capitalization (with the turnover) is the variable with the strongest correlation with CEOs compensations in the data, about 0.4. The market capitalization is defined as the share price at the 31 december multiplied by the number of shares outstanding. The data are available for different

\footnotetext{
${ }^{3}$ Statistical source INSEE.

${ }^{4}$ The National Institute for statistics and Economic Studies.
} 
numbers of firms depending on the year. Respectively for 2003, 2004 and 2005 there are 64, 93 and 52 firms.

Technology and matching The most simpliest increasing positive-value function is choosen: $Y(t, s)=(1+t) s$. In the data, the positive assortative matching is tested by the spearman coefficient. This coefficient indicates the correlation between the rank of the compensation and the rank of the firm size. The Spearman coefficient is around 0.68 for the year 2004 .

The distribution of firm size parameters: The size distribution kernel density is similar to a Pareto distribution. So, the Pareto index is estimated on the data by maximum likelihood estimator. Estimations equal to 0.3 for 2003, 0.38 for 2004 and 0.37 for 2005. The differences between years could came either from fluctuations of the number of firm available in the index or from changes in the size distribution. The scale parameter of the Pareto distribution is the minimum size of the firm on this market.

The talent distribution parameters: The shape and space parameters $\beta$ and $\mathrm{B}$ are estimated for the french CEO market. The spacing between ability for very high educated individuals is expected to be small according to Gabaix and Landier. The shape parameter is more likely conditional on the screening process which is, as we know different between France and US, all the more in the postgraduate education. Those parameters are expected to induce a concentrated distribution due to the common background (Grandes Ecoles as X or ENA) of almost all the CEOs of Large-cap and Mid-cap. A GMM estimation is performed on equation (13). The results for the years 2003, 2004 and 2005 are summarized in Table 1. The estimates obtained for the three years are very close. The talent distribution represents a subjective assess (for the Board Councils) of the differences between the french CEO. The french underlying ability distribution seems more unequal and less concentrated than the US one, estimated by Gabaix and Landier. For the year 2004, the estimation of $\beta$ is about 2.6 and the estimation of $B$ about $0.12 \quad 10^{-6}$. The market perception of the differences between CEO, the distribution of talents, which is needed to generate the french $\mathrm{CEO}$ earning structure, in a competitive market, is very 


\begin{tabular}{cccc}
\hline $\begin{array}{c}\text { Parameters } \\
\mathrm{K}\end{array}$ & 2003 & 2004 & 2005 \\
$\beta$ & 63 & 92 & 52 \\
\hline \hline \multirow{2}{*}{$B$} & $0.64^{*}$ & $2.59 *$ & $2.38^{*}$ \\
& $0.22^{* *}$ & $0.12 *$ & 0.52 \\
& 0.20 & 0.03 & 1.26 \\
\hline \multirow{2}{*}{ Note: std err; $*$ significant at $5 \% * * 10 \%$}
\end{tabular}

Table 1: GMM estimates of the talent distribution parameters

spread and concentrated in higher talents. Those estimated parameters could be interpreted as an overestimation of the variety of french CEO abilities compared to US one, and the result of the french elitism which leads to CEO with very similar background. This dispersion could also be interpreted as the reflect of better information on the talent of the manager due, by instance, to the strong networks (corporatism) at stake on this french market.

Nevertheless, the two distributions, size and talent, are not independent. This issue is mentioned by Rosen [13] who highlights the difficulties to separate the size effect from the performance one through the joint output. As performance itself does not play any role in this model, there is no effort cost and so no incentives. The CEO is paid for his ex ante talent relative to his competitors. For this purpose, in the estimation, the market capitalisation for the previous year is used in order to instrument size. As analysed by Mullainathan and Bertrand, the CEO could be rewarded for luck. In this model, this luck is immediately included into firm size through increasing assets. As a result, the marginal productivity of CEO increases with the output sensitivity to talent. So, in this model, macroeconomic events enter directly in the compensation. It could be seen as a sort of efficiency wage, which reinforces the pro-cyclical properties of the CEO compensation. In the next section, the french wage distribution is simulated in order to discuss the normative interest of this model. 


\section{Simulations and discussion}

Superstar effect: the demand side

The model is simulated for the 2004 data which are the numerous. The sample contains 92 of the largest publicly-traded firms, the smaller size $\left(s_{0}\right)$ is $2.0710^{8}$, the minimal compensation $\epsilon 208989.5, B=0.1210^{-6}$ and $\beta=2.6$. The simulated CEO compensations reproduces well the main moments of the compensation distribution as shown by the following Figure 2:

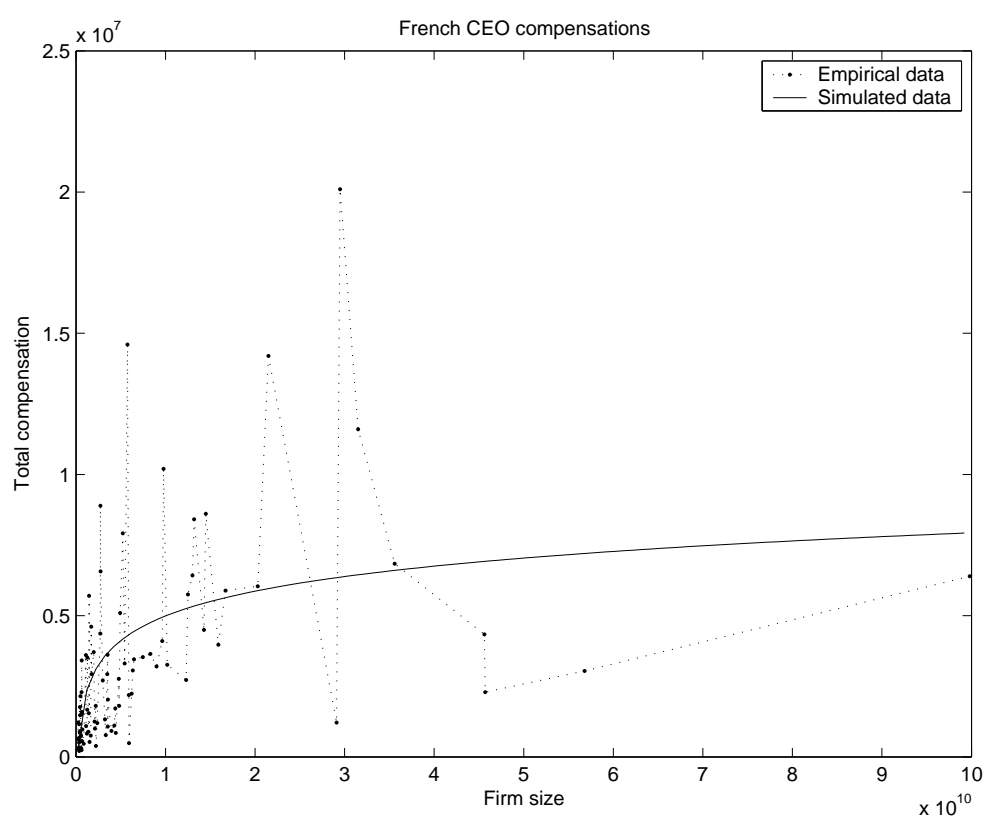

Figure 1: Comparison between empirical and simulated compensations (France 2004)

Such simulations illustrate the wage structure in France, but also provide opportunity to investigate the predicted share that CEO acquires (in a competitive framework) which is decreasing with firm size, from $0.25 \%$ to $0.01 \%$ bracket. As expected, the surplus share is all the more in favour of CEO of smaller firms when the firms concentration is higher. The CEO's share depends on tension on the market at his quantile. This illustrates the stylised fact under which 
CEO of the largest corporations deal with a smaller part of their marginal productivity, which is nevertheless enhances by the size of the firm. The predicted size elasticity of compensation is around 0.5065 for the french parametrization, which is equal to the OLS estimation, on french data, in 2004. The simulations with french parameterization show that a competitive framework is able to reproduce the size elasticity of CEO compensations. A simulation of the US market could be done $\mathrm{f}^{5}$ in order to evaluate the superstar effect on size elasticity of compensations given the french talent distribution. The superstar effect is directly observable on Figure 2. For the French industrial base, the French median elasticity is about 0.5 and should be equal to 0.8 if French CEO were matched with the US distribution of firms. The elasticity of compensations will be equal to 0.8 . The size elaticity of compensations is non-linear with the talent distribution parameter (beta) and varies widely between different financial market.

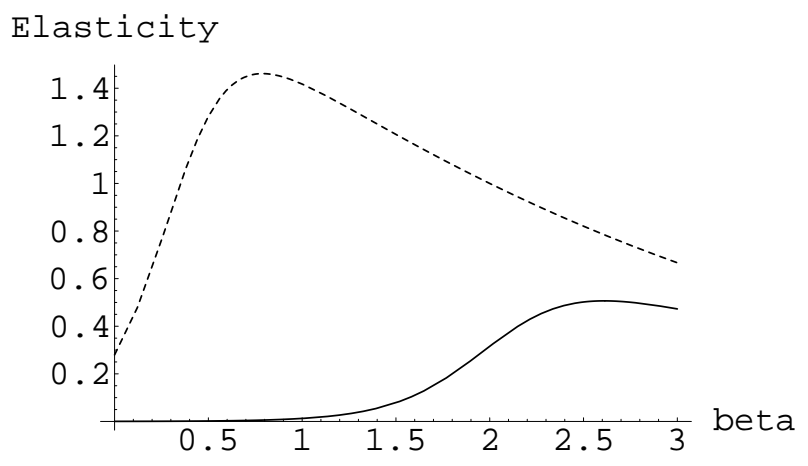

Figure 2: Comparison of the simulated median size elasticity of CEO compensations in a US economy (dash) and in french economy (full)

Recent econometrical studies (Frydman 2005 [2], Frydman and Saks 2007 [3] and Kostiuk 1990), concerning elasticity, reveal a smallest estimation than

\footnotetext{
${ }^{5}$ Estimation of $\beta$ and $B$ of Gabaix and Landier performed through a panel approach but the US median size elasticity of wage simulated with this model is about 1 which is equal to the elasticity found by the authors.
} 
those predicted by this familly of models. ${ }^{6}$ Two explanations are hypothetized. First, lower competition and substitution effects due to more firm-specific skill during far-distant periods. Frydman and Saks already found larger elasticity for more recent periods. Second, a different technological production characterized by a lower CEO impact on global productivity due to a lower complementarity with assets before the NICT revolution. The simulations of size elasticity of CEO compensations according to variable distribution (free beta or alpha) have an explanatory power, both in the sense of the increase in subsitution between CEO through very weak or very high beta and lower value of alpha. The median size elasticity of compensations is non linear with respect to $\beta$ and $\alpha$. Does this variability come from changes in size or in talent distribution functions as suggested in this model? Since the talent is very difficult to measure, the firms anticipation concerning relative talents could explain such differences, like the previous simulations illustrate it. Moreover, the recent shaping of a CEO market in France, due to the latest privatizations could explain the lower levels of compensations in the previous decades as the result of a weaker competition. Does the shift correspond to a shift of French firms attitude towards their CEO: from a monopsony to a more competitive situation? Economists highlighted the shift in skill requirements, regarded as less firm-specific for manager (Frydman). In France, CEO of larger firms have very homogeneous background of civil servant or Grandes Ecoles diploma and as a consequence have outside opportunities in high responsability public jobs. Hence, CEO of largest firms are completely different from the CEO of middle and small firms, indeed their training is very generalist since a long time ago. Nevertheless, their participation to the CEO market has been reinforced since the last privatisation (1993-1997) wave and the introduction of previous public society on the stock exchange.

Superstar effect : the offer side A shift in talent offer is simulated by increasing the talent distribution inequality through First Order Stochastic Dominance. The wage distribution is less scattering as the talent inequality soars the CEO

\footnotetext{
${ }^{6}$ Frydman and Saks estimated a 0.1 elasticity from 1936 to the beginning of the twenty-one century.
} 
compensations of first quantiles and decreases them in higher ones. The differential rents are linked to talent distribution but through a non linear relationship. For a given size, shifts in market perception of differences between CEO could decrease or increase the CEO compensation according to the differential rents. The Uniform productivity growth: with and without free entry A uniform productivity growth increases compensation with the same factor if the reservation prices move in lockstep with the productivity, otherwise there is free entry and the compensations increase a little more. The two cases imply very close compensations structure and median size elasticity of compensation but a higher mean elasticity of compensation for the free entry market. The period of new economy can be modelized as an increase in the talent composition through a higher $\beta$ and a more liquid financial market allowing an increase in $\alpha$ and a uniform productivity growth which leads to an increasing number of firms and CEO on the market resulting in higher compensations on the French market. To illustrate the French actual superstar effect, the loss due to the substitution of the best CEO by the median one in the largest firm is around $0.095 \%$ to compare to the $0.016 \%$ of Gabaix and Landier. The corresponding differential compensation for $\mathrm{CEO}$ is equal to $226 \%$, in this competitive framework with a size elasticity about 0.5. Jasso, Meyerson and Milgrom (2003) worked on macrojustice, through a MBA student survey, and evaluated that the median elasticity of fair CEO compensation with respect to firm size should be in the range of 0.14 to 0.26 . In this competitive framework very few differences between prospective executives justify large magnitudes of compensation whereas precisely, the World Value Survey shows that France is one of the country which is closer to the answer "Incomes should be made more equal " rather than "We need larger income differences as incentives " at the question on income equality. So, the fact that French people frown upon the superstar effect was expected.

In spite of what the market-driven explanation suggests, the question of the regulation of $\mathrm{CEO}$ compensations is raised due to the public interest for the question and the numerous European (Netherlands, Switzerland, Germany and France) policymakers who call for CEO compensation temperance. Indeed, 
Code of Best Practice, made public in France (95 and 99 Viénot reports, 2002 Bouton report) to moderate those compensations, are inefficent and Board of Adminisatration alone fix the CEO compensation. Nevertheless, some representatives of shareholders, call for a mandatory upper limit. How is it possible? The last section investigates a cap policy and enables us to understand the emergence of protest from shareholders themselves without any equity considerations or changes in the objective function (maximization of shareholder value rather than stakholder value).

\section{Compensation cap policy}

The salary cap terminology derives from the professional sports vocabulary. More precisely, from team sports like Basketball or Baseball which leagues use cap to moderate the team compensation by the introduction of an upper limit envelope based on league revenues. In this paper, the effect of individual cap is investigated for the CEO. Until now, only limits on the deductibility of executive pay, like the OBRA in United-States, have been implemented. This policy have been assessed by Rose and Wolfram [7]. Their results suggest that the growth of total pay, for limited firms, decreases slightly and that the structure of compensation changes in favor of non salary pay. Evaluate the effect of a cap policy in a sorting framework makes sens as the main economic issue is: how attract the best manager? Most of the time incentives are not mentioned to justify the levels of CEO compensations (in France). An upper limit $\bar{w}$ is implemented, it concerns executives whom firms size is above the threshold $\bar{s}$ such that:

$$
\forall s \geqslant \bar{s} \quad w(s)=\bar{w}
$$

In this case, compensations can no longer play their allocative role and the positive allocation becomes a random matching for all the firms above this upper limit. The equation (17) describes the expected production for a firm whose size 


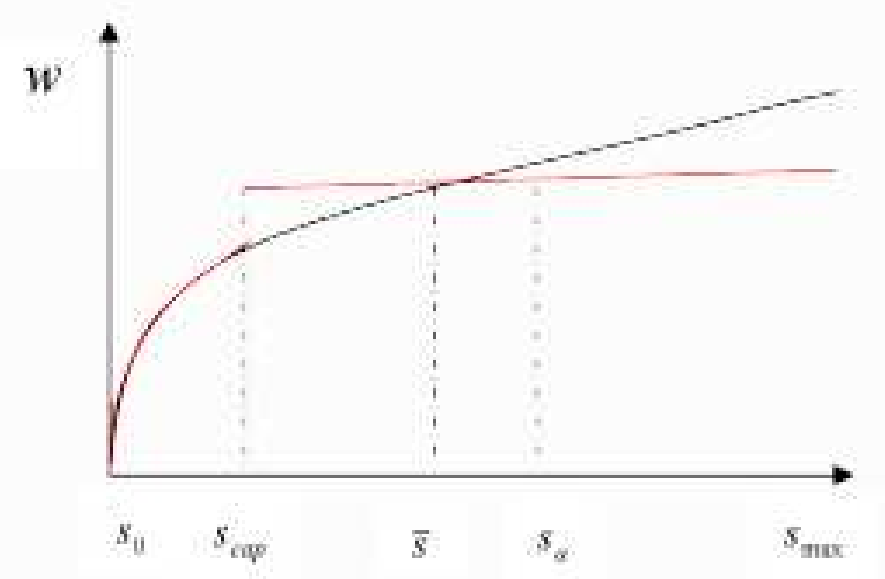

Figure 3: Compensation structure: Positive Assortative compensation (black line) and new equilibrium with the upper limit (red line)

$s$ is above the threshold:

$$
E_{t}(Y(t, s))=\int_{\varphi(\bar{s})}^{t_{\max }} \frac{Y(x, s)}{1-F(\varphi(\bar{s}))} \mathrm{dF}(x)
$$

A new equilibrium stands out. Indeed, each firm who fix freely the CEO compensation must do a trade-off between hire his "positive assortative matching" $\mathrm{CEO}$ at the equilibrium price or try to attract a most talented CEO in average by offering exactly the compensation cap:

$$
\operatorname{Max} \underbrace{Y(\varphi(s), s)-w(s)}_{P A M} \quad \underbrace{Y\left(t_{p}(s), s\right)-\bar{w}}_{\text {cap }}
$$

A firm who posts the upper limit compensation expects to be matched with a CEO with an expected talent denoted $t_{p}$ which is equal to the average talent above the rank of the talent allocated with the firm at the PAM equilibrium. This expected talent, $t_{p}$, is higher than the one with positive assortative matching, $\varphi(s)$. Their difference corresponds to a variation of compensation equals to $\frac{\alpha K^{\beta} B s_{\alpha}^{\alpha \beta}}{1-\alpha \beta}\left(s_{p}^{1-\alpha \beta}-s^{1-\alpha \beta}\right)$. The existence of firms which set voluntarily a compensation equals to the wage cap in order to attract a most talented manager depends on the size of their firm. If the size is above the following threshold then the firm sets the upper limit compensation:

$$
s_{c a p}=\left(\frac{\frac{\alpha}{1-\alpha \beta}}{\frac{1}{1+\beta}+\frac{\alpha}{1-\alpha \beta}}\right)^{\frac{1}{1-\alpha \beta}} \bar{s}
$$


This trade-off implies a wider mismatch than expected. The smallest firms obtain a best joint production at the expense of the largest. The losses inferred by the cap are always larger for the largest firms concerned. Indeed, the CEO they attract is less talented in average than their $\mathrm{CEO}$ with positive assortative matching. To assess the loss inferred by the cap policy, the average aggregate effect is calculated for the production $(\Delta Y)$, the shareholder value $(\Delta \pi)$ and the average loss for CEO $(\Delta w)$. The global loss is given in proportion of the total market capitalization in the second column of the Table 2. The two last columns indicate respectively: in the column intitled "YES", the percentage of shareholders who realize positive gain thanks to the setting up of the compensation cap policy, in the "NO" column, the shareholder who lose. These two percentages are calculated according to the weight of each firm (capitalization), assuming that the biggest firms have more shareholders. Indeed, the correlation between the market capitalization and the number of shares outstanding is above 0.8. For sufficiently high level of wage cap, i.e 6.4 million euro, the shareholders whose firms are concerned by the upper limit are a majority to call for a cap policy (the proportion reported in the "YES" column of the Table 2). Under the six million cap there is no ambiguity, whereas above, the majority depends on the say of the sharholders who are not concerned by the compensation cap (the supplementary percentage). Nevertheless, CEO whom talent belongs to the $\left[\varphi\left(s_{c a p}\right), \varphi(\bar{s})\right]$ are better paid than before the cap policy. They are paid above their marginal productivity. Actually, for a six million cap, the mean CEO compensation runs down by $7.4 \%$, it represents a decrease about half million euro in average. This six million cap is equivalent to 250 French average salary and equivalent to 430 minimum wage (2004). When a six million cap is implemented, $20 \%$ of the sample is concerned which represents $73.3 \%$ of the global capitalisation. This model gives an interpretation of the increasing proxy fight which took place during the annual meeting of some of the biggest French firms. Moreover, the assess of such a compensation cap is done by using a random matching function instead of a positive assortative matching. However, it is without taken into account the information held by the investors about 
prospective $\mathrm{CEO}$, and their commitment to enterprise (if they were already on the market). Those informations may help to have a better matching function that expected without the signal of the compensation.

\begin{tabular}{|c|c|c|c|c|c|c|}
\hline $\begin{array}{c}\bar{w} \\
\text { (in million euro) }\end{array}$ & $\begin{array}{c}\Delta Y_{\text {Global }} \\
(\%)\end{array}$ & $\begin{array}{c}\Delta Y \\
(\%)^{*}\end{array}$ & $\begin{array}{c}\Delta w \\
(\%)^{*}\end{array}$ & $\begin{array}{c}\Delta \pi \\
(\%)^{*}\end{array}$ & $\begin{array}{c}\text { YES } \\
(\%)\end{array}$ & $\begin{array}{c}\text { NO } \\
(\%)\end{array}$ \\
\hline \hline 1.68 & -0.115 & -0.093 & -46.8 & -0.074 & 7.6 & 91.6 \\
2.97 & -0.058 & -0.03 & -29.4 & -0.020 & 13.5 & 82.7 \\
3.63 & -0.04 & -0.016 & -23.2 & -0.009 & 17.9 & 75.9 \\
4.5 & -0.024 & -0.007 & -16.4 & -0.003 & 24.6 & 64.4 \\
5 & -0.017 & -0.0043 & -13.1 & -0.0013 & 29 & 56.2 \\
6 & -0.0077 & -0.0013 & -7.4 & -0.00004 & 37 & 36.3 \\
6.4 & -0.005 & -0.0007 & -5.3 & 0.00008 & 38.4 & 27.6 \\
7 & -0.0019 & -0.0002 & -2.3 & 0.00007 & 36.2 & 12.8 \\
7.5 & -0.0006 & -0.00005 & -0.8 & 0.00003 & 27 & 4.4 \\
\hline
\end{tabular}

Note: $*$ in average

Table 2: Evaluation of the losses and shareholder's votes about the compensation cap policy

\section{Conclusion}

The analysis of the French CEO compensations in a competitive framwork is able to reproduce the main moments of the distribution and to provide interesting counterfactuals for France. Nevertheless, the comparaison of the simulated data with the empirical data shows that French CEO compensations are less regular than those generated by the differential rent modelling. Indeed, the Spearman coefficient is not equal to one and some other machanisms may play a role in the determination of CEO compensations through more complex matching technology or others market imperfections. As a conclusion, French CEO compensations could not be understood as the simple result of a competitive process of matching, even if those models are the only one able to modelize the 
levels of CEO compensations in a general framework with a very simple design. This framework allows the French CEO compensations to be linked with the globalisation process and the offer of talent without the scarcity excuse. The last section gives an assess of the cost of a compensation cap policy. This cost is moderate and even, for sufficiently high caps, attractive for shareholders. The existence of shareholders lobbies against large amounts of compensation are explainable on such a sorting model without specifying an other objective function which would take into account the opinon of stakeholders. Such a policy is costly and could hardly be implemented with the approval of the shareholders, it depends of the composition of the shareholding of companies.

\section{References}

[1] A.SCHOAR and M.BERTRAND. Managing with style : The effect of managers on firm policies. The Quaterly Journal of Economics, 118:11691208, November 2003.

[2] C.FRYDMAN. Rising through the ranks : the evolution of market for corporate executives 1936-2003. Under revision, 2005.

[3] C.FRYDMAN and R. SAKS. Executive compensation: A new view from a long-run perspective, 1936-2005. July 2007.

[4] X. GABAIX and A. LANDIER. Why has ceo pay increase so much? Quarterly Journal of Economics, avril 2007.

[5] G.BECKER. A theory of marriage. Journal of Political Economy, 81, August 1973.

[6] H.TAKAYASU and K.OKUYAMA. Country dependenceon company size distributions and a numerical model based on competition and cooperation. Fractals, 6(1):67-79, 1998. 
[7] N L.ROSE and C. WOLFRAM. Regulating executive pay: Using the tax code to influence executive compensation. Journal of Labor Economics, (20 (part2)), April 2002.

[8] M.SATTINGER. Assignment models of the distribution of earnings. Journal of Economic Literature, 31(2), Juin 1993.

[9] M.TERVIO. The difference that ceos make: An assignment model approach. February 2007.

[10] R M.COSTRELL and GC.LOURY. Distribution of ability and earnings in a hierarchical job assignment model. May 2004.

[11] R.AXTELL. Firm sizes: Facts, fables and fantaisies. CSED Working Paper, (44), February 2006.

[12] S.ROSEN. The economics of superstars. The American Economic Review, 71(5), December 1981.

[13] S.ROSEN. Contracts and the market for executives. NBER Working Papers series, December 1990. 


\section{CESifo Working Paper Series}

for full list see www.cesifo-group.org/wp

(address: Poschingerstr. 5, 81679 Munich, Germany, office@cesifo.de)

2337 Sumon Majumdar and Sharun W. Mukand, The Leader as Catalyst - on Leadership and the Mechanics of Institutional Change, June 2008

2338 Ulrich Hange, Tax Competition, Elastic Labor Supply, and Growth, June 2008

2339 Guy Laroque and Bernard Salanié, Does Fertility Respond to Financial Incentives?, June 2008

2340 Adriano Paggiaro, Enrico Rettore and Ugo Trivellato, The Effect of Extending the Duration of Eligibility in an Italian Labour Market Programme for Dismissed Workers, June 2008

2341 Helmut Seitz, Minimum Standards, Fixed Costs and Taxing Autonomy of Subnational Governments, June 2008

2342 Robert S. Chirinko, Leo de Haan and Elmer Sterken, Asset Price Shocks, Real Expenditures, and Financial Structure: A Multi-Country Analysis, July 2008

2343 Wolfgang Leininger, Evolutionarily Stable Preferences in Contests, July 2008

2344 Hartmut Egger and Udo Kreickemeier, Fairness, Trade, and Inequality, July 2008

2345 Ngo Van Long and Bodhisattva Sengupta, Yardstick Competition, Corruption, and Electoral Incentives, July 2008

2346 Florian Baumann, Employment Protection: The Case of Limited Enforceability, July 2008

2347 Alessandro Balestrino, Cinzia Ciardi and Claudio Mammini, On the Causes and Consequences of Divorce, July 2008

2348 Dirk Schindler and Benjamin Weigert, Insuring Educational Risk: Opportunities versus Income, July 2008

2349 Lammertjan Dam and Ben J. Heijdra, The Environmental and Macroeconomic Effects of Socially Responsible Investment, July 2008

2350 Avner Greif, Contract Enforcement and Institutions among the Maghribi Traders: Refuting Edwards and Ogilvie, July 2008

2351 Helmuth Cremer, Philippe De Donder, Dario Maldonado and Pierre Pestieau, Habit Formation and Labor Supply, July 2008

2352 Francesco Menoncin and Paolo M. Panteghini, The Johansson-Samuelson Theorem in General Equilibrium: A Rebuttal, July 2008 
2353 Michael Kaganovich and Itzhak Zilcha, Alternative Social Security Systems and Growth, July 2008

2354 Keith Blackburn, Kyriakos C. Neanidis and M. Emranul Haque, Corruption, Seigniorage and Growth: Theory and Evidence, July 2008

2355 Edward Castronova, A Test of the Law of Demand in a Virtual World: Exploring the Petri Dish Approach to Social Science, July 2008

2356 Harald Badinger and Peter Egger, GM Estimation of Higher-Order Spatial Autoregressive Processes in Cross-Section Models with Heteroskedastic Disturbances, July 2008

2357 Wolfgang Buchholz and Jan Schumacher, Discounting the Long-Distant Future: A Simple Explanation for the Weitzman-Gollier-Puzzle, July 2008

2358 Luca Anderlini, Leonardo Felli and Alessandro Riboni, Statute Law or Case Law?, July 2008

2359 Guglielmo Maria Caporale, Davide Ciferri and Alessandro Girardi, Are the Baltic Countries Ready to Adopt the Euro? A Generalised Purchasing Power Parity Approach, July 2008

2360 Erkki Koskela and Ronnie Schöb, Outsourcing of Unionized Firms and the Impacts of Labour Market Policy Reforms, July 2008

2361 Francisco Alvarez-Cuadrado and Ngo Van Long, A Permanent Income Version of the Relative Income Hypothesis, July 2008

2362 Gabrielle Demange, Robert Fenge and Silke Uebelmesser, Financing Higher Education and Labor Mobility, July 2008

2363 Alessandra Casarico and Alessandro Sommacal, Labor Income Taxation, Human Capital and Growth: The Role of Child Care, August 2008

2364 Antonis Adam, Manthos D. Delis and Pantelis Kammas, Fiscal Decentralization and Public Sector Efficiency: Evidence from OECD Countries, August 2008

2365 Stefan Voigt, The (Economic) Effects of Lay Participation in Courts - A Cross-Country Analysis, August 2008

2366 Tobias König and Andreas Wagener, (Post-)Materialist Attitudes and the Mix of Capital and Labour Taxation, August 2008

2367 Ximing Wu, Andreas Savvides and Thanasis Stengos, The Global Joint Distribution of Income and Health, August 2008

2368 Alejandro Donado and Klaus Wälde, Trade Unions Go Global!, August 2008

2369 Hans Gersbach and Hans Haller, Exit and Power in General Equilibrium, August 2008 
2370 Jan P.A.M. Jacobs and Jan-Egbert Sturm, The Information Content of KOF Indicators on Swiss Current Account Data Revisions, August 2008

2371 Oliver Hülsewig, Johannes Mayr and Timo Wollmershäuser, Forecasting Euro Area Real GDP: Optimal Pooling of Information, August 2008

2372 Tigran Poghosyan and Jakob de Haan, Determinants of Cross-Border Bank Acquisitions in Transition Economies: A Latent Class Analysis, August 2008

2373 David Anthoff and Richard S.J. Tol, On International Equity Weights and National Decision Making on Climate Change, August 2008

2374 Florian Englmaier and Arno Schmöller, Reserve Price Formation in Online Auctions, August 2008

2375 Karl Farmer, Birgit Friedl and Andreas Rainer, Effects of Unilateral Climate Policy on Terms of Trade, Capital Accumulation, and Welfare in a World Economy, August 2008

2376 Monika Bütler, Stefan Staubli and Maria Grazia Zito, The Role of the Annuity’s Value on the Decision (Not) to Annuitize: Evidence from a Large Policy Change, August 2008

2377 Inmaculada Martínez-Zarzoso, The Impact of Urbanization on $\mathrm{CO}_{2}$ Emissions: Evidence from Developing Countries, August 2008

2378 Brian Roberson and Dmitriy Kvasov, The Non-Constant-Sum Colonel Blotto Game, August 2008

2379 Ian Dew-Becker, How Much Sunlight Does it Take to Disinfect a Boardroom? A Short History of Executive Compensation Regulation, August 2008

2380 Cécile Aubert, Oliver Falck and Stephan Heblich, Subsidizing National Champions: An Evolutionary Perspective, August 2008

2381 Sebastian Buhai, Miguel Portela, Coen Teulings and Aico van Vuuren, Returns to Tenure or Seniority?, August 2008

2382 Erkki Koskela and Jan König, Flexible Outsourcing, Profit Sharing and Equilibrium Unemployment, August 2008

2383 Torberg Falch and Justina AV Fischer, Does a Generous Welfare State Crowd out Student Achievement? Panel Data Evidence from International Student Tests, September 2008

2384 Pedro Gomes and François Pouget, Corporate Tax Competition and the Decline of Public Investment, September 2008

2385 Marko Koethenbuerger, How Do Local Governments Decide on Public Policy in Fiscal Federalism? Tax vs. Expenditure Optimization, September 2008 
2386 Ronald McKinnon and Gunther Schnabl, China's Exchange Rate Impasse and the Weak U.S. Dollar, September 2008

2387 Yan-Leung Cheung, Yin-Wong Cheung and Alan T.K. Wan, A High-Low Model of Daily Stock Price Ranges, September 2008

2388 Louis Eeckhoudt and Harris Schlesinger, Changes in Risk and the Demand for Saving, September 2008

2389 Carsten Hefeker and Blandine Zimmer, Uncertainty and Fiscal Policy in an Asymmetric Monetary Union, September 2008

2390 Jay Pil Choi and Byung-Cheol Kim, Net Neutrality and Investment Incentives, September 2008

2391 Marcel Gérard, Financing Bologna, the Internationally Mobile Students in European Higher Education, September 2008

2392 Annette Alstadsæter and Knut Reidar Wangen, Corporations' Choice of Tax Regime when Transition Costs are Small and Income Shifting Potential is Large, September 2008

2393 António Afonso and Christophe Rault, 3-Step Analysis of Public Finances Sustainability: the Case of the European Union, September 2008

2394 Betsey Stevenson and Justin Wolfers, Economic Growth and Subjective Well-Being: Reassessing the Easterlin Paradox, September 2008

2395 Bernhard Eckwert and Itzhak Zilcha, Private Investment in Higher Education: Comparing Alternative Funding Schemes, September 2008

2396 Øystein Foros, Hans Jarle Kind and Jan Yngve Sand, Slotting Allowances and Manufacturers’ Retail Sales Effort, September 2008

2397 Mohammad Reza Farzanegan, Illegal Trade in the Iranian Economy: Evidence from a Structural Model, September 2008

2398 Olivier Bos, Charity Auctions for the Happy Few, September 2008

2399 Robert S. Chirinko and Debdulal Mallick, The Marginal Product of Capital: A Persistent International Puzzle, September 2008

2400 Ben D’Exelle and Arno Riedl, Elite Capture, Political Voice and Exclusion from Aid: An Experimental Study, September 2008

2401 Torben M. Andersen and Joydeep Bhattacharya, On Myopia as Rationale for Social Security, September 2008

2402 Fabienne Llense, French CEO Compensations: What is the Cost of a Mandatory Upper Limit?, September 2008 